\title{
La legitimación democrática del poder supranacional
}

\author{
Miryam Rodríguez-Izquierdo Serrano \\ Profesora Ayudante Doctora de Derecho Constitucional \\ Universidad de Sevilla
}

Recibido: 01.10.2012

Aceptado: 15.10.2012

\begin{abstract}
Resumen: El presente artículo realiza un análisis crítico de los modelos conocidos que explican o articulan la legitimación del poder supranacional utilizando con la Unión Europea como paradigma. El objetivo consiste en establecer en qué medida cada uno de ellos está más cerca o más lejos de las coordenadas del constitucionalismo democrático -soberanía popular y derechos, imperio de la ley-. A través del texto se describiendo el que sería, según la autora, el modelo ideal.
\end{abstract} nalismo.

Palabras clave: Legitimación democrática, supranacionalidad, constitucio-

Abstract: This article analyzes critically the different doctrinal justification of the legitimacy of the supranational power, using the EU as the reference example. The aim of this paper is to establish to what extent each one of the models respect the democratic standards (sovereignty, human rights, rule of law). Besides, the text does propose the ideal model.

Key words: Democratic legitimacy, supranationality, constitutionalism.

Sumario: Introducción: Los retos globales del paradigma democrático.- 1. La legitimación a través del Derecho.-1.1. El modelo iusinternacional y la autonomía del orden europeo.-1.2. El modelo del pluralismo constitucional.-2. La legitimación institucional.-2.1.El modelo institucional europeo: Consejo, Parlamento y Comisión.-2.2.-El modelo institucional integrado: la incorporación de los parlamentos nacionales.-3. La legitimación procedimental.-3.1. El modelo de la subsidiariedad.-3.2. El inquietante modelo de la gobernanza.- - 4.Conclusión

\section{INTRODUCCIÓN: LOS RETOS GLOBALES DEL PARADIGMA DE- MOCRÁTICO}

Cuando hace un año me propusieron que elaborara un trabajo bajo el título La legitimación democrática del poder supranacional, el mensaje de correo electrónico que con la propuesta iba con el siguiente asunto: «un reto desde la UNED». Al estímulo que para cualquier investigador supone la palabra reto, en mi caso se sumó de inmediato el de la oportunidad de enfrentarme a un tema directamente relacionado con la dimensión constitucional de la integración supranacional y hacerlo desde una perspectiva teórica de sumo interés. Ese reto que se me puso por delante se fue multiplicando a medida 
que fui anotando ideas para plantear el análisis, pues iba acumulándose un número importante de ellas, algunas más conexas y otras más extravagantes, mientras que a mí no se me escapaba que para tratar una cuestión como la legitimación democrática del poder más allá del Estado había que hilar muy fino. Y cualquiera que haya profundizado en la perspectiva constitucional de los procesos de integración supranacional estará de acuerdo conmigo en que no es una cuestión fácil de hilar. Un segundo reto era dar un contexto apropiado a un trabajo científico que no puede ser más que teórico en un momento de crisis económica, como el actual, en el que parece-aunque como intentaré demostrar es solo una apariencia-, que los problemas de legitimación democrática son menores, o que simplemente son eso, teóricos, porque lo que de verdad importa es la viabilidad y eficacia de las soluciones que los que ostentan el poder -sea cual sea- ofrezcan a las sociedades, bien sean consideradas en tanto sociedades nacionales, comunidades supranacionales o como comunidad internacional. Y en tercer lugar estaba el reto originario: tratar sobre un objeto de estudio como la legitimación democrática del poder supranacional que en realidad no existe como tal.

El reto de los retos, por tanto, era que estaba obligada bien a trabajar sobre una premisa imposible, bien a recurrir a debates circulares sobre la existencia-inexistencia-posibilidad de un demos más allá del Estado nación, debates que, en concreto para el caso de la Unión Europea, son de sobra conocidos y que, sin subestimar lo que aportan algunos de ellos, en general están algo viciados ${ }^{1}$. El escaso atractivo de esa segunda alternativa, me dejaba solo la primera: la de la premisa imposible. Y así es como decidí que había que plantear la cuestión, empezando por afirmar con toda calma que la legitimación democrática del poder supranacional no existe para entrar, gracias a ese pie, en el terreno de las ficciones. Por suerte, ese terreno era el apropiado, puesto que tanto la legitimación democrática como su fundamento, la soberanía popular, ya son en sí ficciones, modelos creados para sustituir la legitimidad anterior, la de los reyes soberanos, que se desmoronaba mientras en una Europa minada por revoluciones y guerras avanzaban con firmeza las ideas de la ilustración.

${ }^{1}$ Explica CRUz Villalón que la formulación del debate como existencia o ausencia de Volk, "con las inevitables resonancias de la palabra», ha condicionado en gran medida este debate que, en parte, «se encuentra hoy más bien trasladado a la denuncia de falta de un espacio común europeo de información, de formación de opinión pública y de control de la actividad pública». CruZ Villalón, P., La constitución inédita, Trotta, Madrid, 2004, p. 38. Las referencias fundamentales en el debate sobre el demos están en el volumen 1 de la revista European Law Journal, en especial: GrIMM, D., «Does Europe need a Constitution?», European Law Journal, vol 1. (1995), pp. 282-302; HABERMAS, J., «Remarks of Dieter Grimm's 'Does Europe need a Constitution?'», European Law Journal, vol 1. (1995), pp. 303-307.; o WeILleR, J. H.H., «Does Europe need a Constitution? Demos, Telos and the German Maastricht Decision», European Law Journal, vol 1. (1995), pp. 219-258. 
La legitimidad democrática fue un modelo imaginado que en su puesta en práctica y en su evolución fue forjando mecanismos que la traducían en sistemas de gobierno, mejores o peores, en los que la autoridad y actuación de los poderes públicos venía respaldada por una decisión mayoritaria que tenía su origen en una expresión igualitaria de la voluntad ciudadana. Por su parte, el Derecho era otra ficción, una heramienta creada por la sociedad para ordenar y encauzar sus conflictos, que en sí era anterior al paradigma de legitimidad democrática y a sus mecanismos. Esa herramienta adquirió por sí misma una cualidad de elemento legitimador del poder, la legitimidad racional-normativa que explica Max WEBER y que es independiente de su origen consensuado o impuesto ${ }^{2}$. Es justo esa capacidad ordenadora la que hace que el Derecho se presente como el cauce óptimo para subordinar al poder político a unas reglas abstractas, consentidas por todos, que serían la base y a la vez la garantía de la igualdad formal. Es la razón de que el Derecho fuera considerado un aliado en la transición desde la soberanía del monarca a la soberanía nacional. Y, por fin, cuando el constitucionalismo democrático se erigió en el paradigma por antonomasia de los Estados occidentales, ese Derecho, que ordenaba, se integró como elemento del modelo gracias a su vinculación con un doble fundamento: siguiendo a HABERMAS, el doble fundamento del sistema de derechos y la soberanía popular ${ }^{3}$.

Era necesario que soberanía popular y derechos confluyeran, pues los segundos debían sustentar la entidad al sujeto titular de los mismos y hacer posible que este participara en la conformación del poder. Es ese individuo el que forma con otros la comunidad ciudadana, la cual es a su vez la que crea y limita el poder. La legitimidad democrática, por eso, no puede explicarse si no es a través de la identificación de una ciudadanía soberana que responda a ese patrón del constitucionalismo democrático originario, el patrón dado por la nacionalidad y el Estado. Sin esa identificación, que no existe en los sistemas supranacionales de poder público, la legitimación democrática del poder supranacional y de su sistema jurídico tiene la misma conexión con la realidad que el mundo subterráneo de la Alicia de Lewis Carroll. Con ello, la única alternativa que quedaría para aproximarse al tema sería la laberíntica elucubra-

${ }^{2}$ «Hoy en día, la base más usual de la legitimidad es la creencia en la legalidad, la disposición a aceptar las normas formalmente correctas y han sido impuestas por un procedimiento válido. La distinción entre un orden derivado del acuerdo voluntario y otro que ha sido impuesto es relativa. Mientras que el acuerdo que sustenta un orden no sea unánime (...), su funcionamiento en el seno de un grupo social dependerá de la voluntad de los individuos que difieran en sus pretensiones de dar crédito a la mayoría». WEBER, M., The theory of social and economic organization, Free Press, New York, 1964, pp. 131-132. Las traducciones al español de las citas bibliográficas en inglés que figuran en las notas a pie de este artículo son de mi propia autoría.

${ }^{3}$ En relación con la cooriginalidad de sistema de derechos y soberanía popular en la construcción discursiva de lo constitucional, véase Habermas, J., Facticidad y Validez, Trotta, Madrid, 1998, p. 156. 
ción sobre la existencia o inexistencia del demos europeo, pero ese no era el camino que se quería seguir en este estudio. Así que, para salir de la trampa del demos en la que tan difícil es evitar caer, este discurso va a volver a la senda de la ficción, adoptando una lógica parecida a la de las criaturas de ese submundo lewiscarrolliano.

Diría una de esas criaturas, quizás un ratón de campo azul, a una atribulada Alicia.

Si la legitimación democrática del poder supranacional no existe, ¿para qué te preocupas por ella?

-Pues porque es necesario que exista -replicaría nuestra Alicia sin saber muy bien por qué.

-¿Por qué? -se interesaría otra criaturilla, quizás un dado redondo y gordinflón, adivinando la confusión de la niña.

-Porque todo poder tiene que estar legitimado democráticamente. Está establecido así - contestaría nuestra Alicia, una estudiante aplicada de primero de Derecho que hubiera asistido a alguna lección de teoría constitucional.

Entonces el ratón de campo plantearía una nueva cuestión:

-¿Por quién está establecido?

Alicia tendría que pensar antes de responder:

-¿Por un pensador francés de los tiempos de Napoleón? ¿Por los americanos? ¿Por el pueblo? No, ¿cómo era? ¿Por el acuerdo de todos? - diría la niña dubitativa, esperando acertar.

-Pues si es así -se alzarían las criaturas a coro-, que todos acuerden otra cosa, por ejemplo que el poder venga de los árboles centenarios, y fin del problema. ¡A cambiar de lugar!

Como a estos personajes plagiados, puede parecernos que la importancia del tema es relativa, pues si la realidad es que hay instancias ejerciendo poder a nivel supranacional y el ejercicio de ese poder es aceptado por todos, fundamentalmente por los Estados, supuestos titulares exclusivos de la soberanía ad extra, ¿para qué afinar con la explicación acerca de la legitimidad de ese poder? Entonces, preguntarnos por los mecanismos que adopta el poder supranacional, con el referente paradigmático de la Unión Europea, con el fin de justificar su adhesión al paradigma democrático, ¿es una labor superflua? Yo creo que no. Al contrario, está más que justificada porque la inexistencia de legitimación democrática no es banal. La cuestión va más allá del galimatías antes expuesto y, he de insistir, tampoco se resuelve con el inconcluso debate doctrinal sobre el demos. Es más, hasta podría decirse que ese debate desvía la atención y disimula una problemática más apremiante: el hecho de que la globalización, el incremento exponencial de la movilidad transnacional de personas, capitales, transacciones comerciales y financieras, la innegable repercusión mundial de las decisiones locales y la instauración de un modelo de comunicación global a través de internet, que entre otras cosas multiplica las posibilidades de intercambio comercial e informativo, han deshecho esa categoría -el escurridizo demos - y están impulsando su transformación hacia 
otras nuevas. El debate sobre el demos oculta la realidad de que el poder supranacional sí existe, como se demuestra cuando se analiza la situación europea y la dependencia de los Estados de las decisiones del Consejo Europeo y de las actuaciones del Banco Central Europeo, y de que la ausencia de legitimación democrática de ese poder supranacional puede dar paso a otras legitimaciones. Cuando esas formas de legitimación alternativas asimilan categorías y tratan de copiar mecanismos propios de las democracias constitucionales, acercan a las instancias supranacionales que ejercen poder al paradigma democrático. Pero cuando se incorporan otras fórmulas que se justifican de manera autorreferencial -es decir: se justifican porque se utilizan-y no están conectadas con los principios democráticos, las alertas deben saltar. Si los mecanismos que avalan la legitimidad de ciertas decisiones se dan por válidos, sin más o sin contrastar la suficiencia de su calidad democrática, pueden conllevar una aceptación indiferente de las decisiones de cualquier poder en la medida en que sean eficaces.

Un ejemplo de esta situación es la que crean es el de los mecanismos de adopción de decisiones que facilitan que estas sean tomadas a medias por el poder público, a medias por sectores representativos de intereses diversos. Las regulaciones que se consensúan a través de estos mecanismos suelen dejar un amplísimo margen de actuación a los intereses privados y la normatividad que resulta de ellos suele ser más laxa. Cada vez se habla más de soft law, sin olvidar u olvidando que la capacidad ordenadora del soft law no es la misma que la del Derecho. Con ello, puede que los ciudadanos, los que somos sujetos de esos derechos que sustentan el paradigma democrático, estemos perdiendo capacidad de reacción, capacidad de control y capacidad de participación que, al fin y al cabo, es lo que se presupone a un orden democrático.

Descendiendo a un terreno práctico, un ejemplo para ilustrar las amenazas que se producen por las deficiencias en el control democrático del poder supranacional es el del conflicto entre las libertades de comunicación y los derechos de autor en internet, un conflicto que no tiene más remedio que abordarse desde una perspectiva supranacional, ya que las medidas nacionales para encararlo son claramente insuficientes cuando internet permite saltar por encima de cualquiera de ellas. La aproximación a dicho conflicto desde el punto de vista de la Primera Enmienda de la Constitución americana y la libertad del discurso explica que los derechos originados por el copyright para los autores de trabajos científicos y artísticos se justifican, precisamente, en la protección del discurso y en lo necesario que la comunicación libre de contenidos es para la creación de un tejido democrático. Desde ese punto de vista, hablamos de derechos fundamentales en todo momento, aunque en los países de nuestro entorno no es la libertad de comunicación, sino el derecho de propiedad, concretado en propiedad intelectual, el que permite que se deriven derechos de autor. En ambos casos, derechos de autor, propiedad intelectual o protección del copyright, el resultado es la consagración de un objeto jurídico protegido que, además del significado democrático, tiene un alto valor 
comercial. Para los estadounidenses, el valor comercial no desmerece ni menosprecia el contenido de libertad del objeto protegido, que es el discurso. Para los europeos, que nos mostramos más pacatos ante la idea de que algo derivado de un derecho fundamental pueda tener un valor económico, el derecho de autor se concibe como un bien mercantil, más que iusfundamental, por lo que el debate se sitúa de partida en términos diferentes. A escala europea, los derechos de propiedad intelectual han sido regulados para darles una cierta uniformidad dentro de la Unión a través de la Directiva 2001/29/CE del Consejo y el Parlamento sobre derechos de autor ${ }^{4}$. Si se tiene en cuenta la concepción iusfundamental, esa regulación uniforme, que en la Unión Europea es producto de los trabajos conjuntos de la Comisión-Consejo-Parlamento y de la realización de consultas con los sectores implicados, incide en cuestiones que afectan a las libertades de comunicación y de creación artística o investigación científica, como el fair use o las excepciones a la exclusividad de los derechos de autor. Pues bien: por obra de la citada Directiva, esas cuestiones que afectan a libertades se dejan en dos manos. En parte se dejan en manos de la libertad contractual, con el subsiguiente dominio que ejercen las empresas comercializadoras y gestoras de ese tipo de derechos. Por otra parte, y como consecuencia de lo anterior, esas libertades se dejan en manos de la tecnología, pues la amplia libertad que se deja a la regulación privada hace que la publicación de contenidos esté sometida a las posibilidades de bloqueo que proporcionan las soluciones informáticas y, por tanto, las libertades están por segunda vez en manos privadas ${ }^{5}$. El resultado no es nada ortodoxo desde el punto de vista de las libertades. Y no es solo el caso de la propiedad intelectual el que incide en las libertades de comunicación. Algo parecido ocurre con la regulación europea de los medios audiovisuales y, aunque el asunto no está ni mínimamente abordado, con la Directiva sobre el Comercio Electrónico y su incidencia sobre las libertades de comunicación en la red ${ }^{6}$.

4 Directiva 2001/29/CE del Parlamento Europeo y el Consejo del 22 de mayo de 2001 sobre la armonización de ciertos aspectos del derecho de autor y derechos relacionados en la sociedad de la información.

${ }^{5}$ Son reflexiones tomadas del análisis que LuCCHI, N., hace del artículo 6 de la Directiva cuando la misma dispone que son los titulares de derechos de autor, o bien los acuerdos que estos establezcan colectivamente entre ellos o con otras partes implicadas, los que tendrán que tomar las medidas apropiadas para hacer posibles las excepciones a las limitaciones de uso que establece la propia Directiva. Para LUCCHI, «se deduce del texto que, en primera instancia, las regulaciones deben venir de los titulares de derechos y solo subsidiariamente están sometidas a intervención del Estado». LUCCHI, N., Digital media \& Intelectual property, Springer, Berlin-Heidelberg, 2006, p. 59. Véanse también las páginas 93 y ss., donde el autor reflexiona sobre las consecuencias del dominio del contrato como fuente de regulación de los derechos de autor.

${ }^{6}$ Nos referimos a las siguientes directivas: Directiva 89/552/CEE del Consejo, de 3 de octubre de 1989, relativa a la coordinación de determinadas disposiciones legales, reglamentarias y administrativas de los Estados miembros sobre el ejercicio de actividades de radiodifusión televisiva, modificada por la Directiva 2007/65/CE del Parlamento Europeo 
Al margen de la cuestión de la naturaleza jurídica de los derechos de autor, a lo mejor no es una tontería reclamar que decisiones que afectan a libertades vengan avaladas por una legitimidad democrática suficiente y que sean controladas en cuanto a su constitucionalidad de la misma forma en que lo son las leyes del mismo tipo en los Estados miembros de la Unión. No es nada muy distinto de lo que exige la normatividad constitucional del constitucionalismo democrático. Es precisamente eso. Por el mismo motivo, no es superflua la pregunta sobre la legitimación democrática del poder supranacional, ni lo es preguntarnos qué formas de legitimación son reconocibles en la Unión Europea. Por eso, lo que propongo a continuación es repasar algunos de los modelos conocidos que explican o articulan la legitimación $a$ secas del poder supranacional -con la Unión Europea como paradigma-, escrutando en qué medida cada uno de ellos está más cerca o más lejos de las coordenadas del constitucionalismo democrático -soberanía popular y derechos, imperio de la ley-. Un modelo apropiado de legitimación democrática censuraría decisiones que, aun afectando a libertades, se tomaran con la simple perspectiva de los intereses inmediatamente implicados y no con la de toda la ciudadanía, afectada siempre. También censuraría que se establezcan regulaciones de mínimos o con esa normatividad volátil que deja en manos de poderes privados cuestiones que inciden en el ejercicio de libertades.

\section{LA LEGITIMACIÓN A TRAVÉS DEL DERECHO}

Como ya se ha apuntado, el Derecho es uno de los elementos legitimadores del poder que ejerce el Estado, tanto en el orden interno como en el internacional. Dentro de ese esquema, uno de los pilares de la legitimidad del sistema de gobierno y de las decisiones del mismo en un Estado democrático está en la normatividad constitucional. La Constitución es así tanto el elemento legitimador de ese sistema de gobierno a través de los procedimientos que establece para su formación y expresión de voluntad, como la fuente de legitimidad del sistema jurídico estatal, que deriva de ella ${ }^{7}$. Y ese sistema jurídico estatal incluye el Derecho internacional que se convierte al orden interno, bien sea siguiendo un sistema monista o dualista de incorporación. Pero, por su parte, el Derecho internacional tiene su fundamento propio en los principios normativos del ius cogens y en la soberanía estatal. No es un orden democrático ni constitucional, si bien es cierto que, hasta el día de hoy, tampoco ha necesitado o querido serlo ya que cualquier norma adoptada en el ámbito iusinternacional podía ser reconducida al orden constitucional de legitimación estatal.

y del Consejo, de 11 de diciembre de 2007 para adaptarla a las tecnologías digitales. Directiva 2000/31/CE del Parlamento Europeo y del Consejo, de 8 de junio de 2000, relativa a determinados aspectos jurídicos de los servicios de la sociedad de la información, en particular el comercio electrónico en el mercado interior.

${ }^{7}$ Pérez Royo, J., Las fuentes del Derecho, Tecnos, Madrid, 1984, pp. 27 y ss. 
Los problemas habrían acabado aquí si el modelo no se hubiera alterado, pero los procesos de integración supranacional, en especial el de la Unión Europea, han conducido a una mezcla de complejos normativos estatales y supranacionales, creando la necesidad de una comprensión del Derecho que diera legitimidad democrática al entramado normativo de la Unión y a los poderes que en ella se ejercen. Se trata de una superposición de complejos normativos que no es fácil encuadrar en modelos conocidos. Para dar cuenta de calidad democrática de tal superposición no sirve el modelo kelseniano, con su visión piramidal con cúspide en el Derecho internacional, puesto que desde la misma no puede avistarse un panorama democrático. El referido modelo constitucional estatal, con raíz en la soberanía popular y el sistema de derechos, tampoco sirve para conectar un complejo institucional y normativo como puede ser el de la Unión Europea con una legitimidad de origen de carácter democrático, simplemente porque ese complejo normativo supranacional se postula como un sistema con una autonomía propia y no adquirida a través de los Estados.

Desde los años noventa ha habido una búsqueda de modelos posibles para dar al orden normativo supranacional de la Unión Europea una apoyatura democrática. Entre esos intentos destacan dos: el que se basa en el origen iusinternacional de los Tratados europeos y les da autonomía propia a partir de una ruptura de estos con ese mismo orden y de una posterior conexión de los Tratados con los principios propios del constitucionalismo; y el que habla de un constitucionalismo pluralista como marco normativo de legitimidad de la Unión.

\subsection{El modelo iusinternacional y la autonomía del orden europeo}

El Derecho de los Tratados y el poder supranacional que estos crean puede situarse en un esquema conectado con el paradigma democrático cuando se piensa que son Estados soberanos y democráticos los que dan origen a una organización internacional. El cumplimiento de los protocolos propios del Derecho internacional da legitimidad a esa creación, por un lado, mientras que el seguimiento de las normas de ratificación interna en cada Estado lo hacen por otro lado. Este modelo, simplemente explica, como es, que los Estados soberanos se obligan a través de la ratificación de los Tratados a cumplir con lo establecido en los mismos. Los Estados siguen siendo soberanos y la ratificación convencional a través de los mecanismos constitucionales internos es respetada. Por ello, la legitimidad democrática de origen queda establecida. A continuación, cuando los Estados se convierten en destinatarios de las regulaciones elaboradas por las instituciones supranacionales, lo que queda es el Derecho, el imperio de la ley, en su dicción original el rule of law, que pasa a ser la base de legitimación del poder supranacional. El funcionalismo se convierte en la coartada o en el puente entre la legitimidad de origen y de ejercicio, pues en la medida en que los Tratados establecen normas para la consecución de metas comunes, la legitimación de ejercicio del poder pú- 
blico europeo se da por sentada cuando la actuación de dicho poder persigue esos fines comunes ${ }^{8}$. Así es como se justifica la jurisprudencia del Tribunal de Justicia que postula la autonomía del complejo normativo de las Comunidades Europeas a partir de los años sesenta y así es como se sostienen principios tales como el efecto directo más allá de los Reglamentos y la primacía dentro del ámbito competencial de los Tratados 9 .

Pero precisamente es este esquema tan simple el que lleva mucho tiempo siendo criticado. Como señala Armin VON BOGDANDY ${ }^{10}$ en un reciente trabajo sobre el significado democrático de los artículos 9 a 12 del Tratado de la Unión, el esquema iusinternacional es insuficiente. Y, como explicó Joseph H. H. WeILER hace bastante tiempo, a medida que se fueron ampliando las competencias atribuidas a la Unión, y a medida que el Tribunal de Justicia fue dando una lectura expansiva al contenido de los Tratados, el debate en torno a los límites del ejercicio de competencias, el famoso conflicto de los ultravires, saltó a la palestra ${ }^{11}$. El Tribunal constitucional alemán ya hizo ver en su sentencia sobre Maastricht que detrás del control del ejercicio competencial está el principio democrático. Desde entonces el funcionalismo ha perdido fuerza legitimadora. El poder supranacional no está legitimado siempre solo porque se dirija a conseguir fines comunes. Hace falta más.

La objeción principal a este modelo de la autonomía de los Tratados es esa: que señala una legitimidad de origen suficiente para el momento fundacional, pero no para el desarrollo normativo e institucional europeo. El funcionalismo ha dejado de servir de coartada. Las decisiones europeas van más allá de lo económico desde hace tiempo y de una manera muy clara. Si pensamos en el pacto fiscal, por ejemplo, el mismo supone una ampliación de la capacidad de influencia de la Unión sobre las políticas públicas estatales, una pérdida de autonomía, otra más, que los Estados suman, o más bien restan, a la entregada con la moneda. No se trata solo de que el modelo de la autonomía

${ }^{8}$ Como explica Von Bogdandy, A., «los primeros principios específicos» del constitucionalismo europeo, «tal como los desarrolló Ipsen, nominalmente integración y supranacionalidad, estaban basados directamente en la realización de las tareas del artículo 2 del Tratado de la Comunidad Económica Europea y tenían escasa relación con las tradicones de la doctrina constitucional», VON BOGDANDY, A. «Constitutional principles» en VON Bogdandy, A. y Bast, J., Principles of European Constitutional Law, Hart Publishing, Oxford-Portland, 2006, pp. 3-52, p. 7.

${ }^{9} \mathrm{La}$ exposición de referencia de este proceso es la de STEIN, E., «Lawyers, judges and the making of a transnational constitution», American Journal of International Law, vol 75, núm. 1, 1981, pp. 1-27.

${ }^{10}$ Von Bogdandy, A., «The European Lesson for International Democracy. The Significance of Articles 9 to 12 EU Treaty for International Organizations», Jean Monnet Working Paper Series, núm. 02/11 (2011), http://centers.law.nyu.edu/jeanmonnet/papers/11/110201.pdf.

${ }^{11}$ WeILER, J. H. H., «La transformación de Europa» en WeILER, J. H. H., Europa, fin de siglo, Centro de Estudios Constitucionales, Madrid, 1995, p. 52 y ss. Sentencia Maastricht, BVerfGE 89, 155, de 21 de diciembre de 1993. 
del sistema europeo carezca de una incorporación suficiente de la ciudadanía europea, sino que falta una explicación de esa autonomía arrogada que la conecte con un principio democrático además de la sujeción al imperio de la ley.

Y, para complicar aún más las posibilidades del modelo, es sabido que el ordenamiento europeo se ha postulado como autónomo no solo en relación con los Estados miembros, sino también en relación con el orden internacional, como afirmó el Tribunal de Justicia en su Dictamen 1/91 sobre el Espacio Económico Europeo ${ }^{12}$. Esta segunda dimensión de la autonomía deja otros tantos flecos sueltos. Uno de ellos: si nos encontramos con que los Tratados han adquirido una especificidad propia, ¿por qué su reforma y ratificación aún siguen los protocolos propios del Derecho internacional? ¿No debería cambiar el sistema de ratificación para que se pudiera identificar a través de él el origen de su legitimidad, distinta, según se postula, de la del resto de tratados internacionales? Insistiré sobre este asunto más adelante. Aquí dejo apuntado que, en cierto sentido, la misma jurisprudencia del Tribunal de Justicia que dio autonomía a los Tratados europeos, también los dejó fuera del contexto de su legitimidad original y, desde entonces, el modelo ha quedado cojo.

\subsection{El modelo del pluralismo constitucional}

A la insuficiencia del modelo iusinternacional para explicar la autonomía del orden europeo, y ante la necesidad de dar una cobertura constitucional a la Unión, se ha reaccionado con la elaboración de varias concepciones que aquí aglutino, no sé si un poco a la ligera bajo el amplio paraguas del pluralismo como modelo constitucional. Dicho modelo pretende explicar la convivencia de una pluralidad de complejos normativos de naturaleza constitucional, interrelacionando la concepción autónoma y constitucional de los Tratados con la de los órdenes constitucionales de los Estados miembros. De ahí surge un espacio constitucional europeo que, siguiendo a Peter HÄBERLE $^{13}$, presuponen una cultura constitucional uniforme basada en el sistema de derechos y en el imperio de la ley. El concepto de pluralismo constitucional, frente al de pluralidad, tiene un contenido axiológico ínsito, pues presupone que el sistema óptimo para el mantenimiento de poderes constitucionales en concurrencia y colaboración está estructurado de tal manera que cada complejo normativo parcial, bien sea estatal, subestatal o supranacional, depende en mayor o menor medida de la existencia y del apropiado desenvolvimiento del resto. No son, por tanto, modelos meramente descriptivos de la pluralidad

${ }^{12}$ Opinión 1/91 del Tribunal de Justicia, Opinión C-1/91, de 14 de diciembre de 1991, ECR 1991, p. I-6079.

${ }^{13}$ HäBerle, P., «¿Existe un espacio público europeo?», Revista de Derecho Comunitario Europeo, núm. 3, 1998, pp. 113-136. 
normativa y de la competencia que se dan en el seno de los sistemas supranacionales que ejercen poder político. Son modelos que orientan la comprensión de tal complejidad hacia un principio prefijado que se establece como valor a realizar, el del pluralismo, elemento a mantener y a reproducir tanto en la estructura como en el funcionamiento de los complejos normativos integrados.

La vía de legitimación que se postula con el pluralismo constitucional se apoya, como he indicado, en la legitimación a través del Derecho. Y, si bien quiere situar al poder supranacional en la línea de la legitimidad democrática del constitucionalismo estatal, no tiene más remedio que reformular los elementos clásicos del mismo, de manera que estos puedan explicar o aplicarse en igual medida al constitucionalismo estatal y al supranacional. Esa reformulación de conceptos clásicos es radical, es decir, no hay ni un solo elemento de la Teoría de la Constitución que quede como estaba: es necesario dar un nuevo sentido al Estado constitucional y se empieza a hablar de Estados cooperativos, como hace HÄBERLE, y de Estados integrados, como hace LÓPEZ CASTILLO $^{14}$; es necesario aceptar que el poder público supranacional es también un poder constitucional y avalar la doble teoría de la constitucionalización de los Tratados y la europeización de las Constituciones; y por fin no queda más remedio que concebir una ciudadanía adecuada a la construcción constitucional compuesta, una ciudadanía que incluya la nacionalidad estatal y ese otro elemento ciudadano, la cualidad de europeo, que al margen de suponer una posición jurídica específica -con la serie de derechos aparejados a la ciudadanía que están en los artículos 18 y siguientes del Tratado de Funcionamiento y, como no, en la Carta de Derechos-, reivindica tanto el reconocimiento del sujeto público europeo del que habla Cruz Villalón ${ }^{15}$ como el tratamiento en profundidad de los elementos de identidad europeos.

Estos modelos de pluralismo constitucional son variados y casi todos ellos contienen elementos propios del federalismo. Muchos nombres los bautizan, aunque cada uno es significativo de matices o, mejor dicho, de comprensiones teóricas determinadas: MACCORMICK habla de constitucionalismo mixto o mezclado -mixed- en su Questioning sovereignty ${ }^{16}$; Ingolf PERNICE desarrolla un esquema de constitucionalismo multinivel que concibe el com-

${ }^{14}$ HäBerle, P., Pluralismo y Constitución. Estudios de Teoría Constitucional de la sociedad abierta, Tecnos, Madrid, 2002, p. 123 y ss. El concepto de integración es detalladamente estudiado en López Castillo, A., Constitución e integración, Centro de Estudios Constitucionales, Madrid, 1996.

${ }^{15} \mathrm{El}$ autor vincula esa reivindicación del sujeto público europeo a «en definitiva, una reivindicación de democracia». Cruz Villalón, P., La constitución inédita ..., op. cit., p. 41.

${ }^{16}$ Maccormic, N., Questioning Sovereignty (Law, State, and Nation in the European Commonwealth), Oxford University Press, Oxford, 1999, p. 104. Una explicación del concepto de constitucionalismo mezclado de MacCormick puede encontrarse en FossuM, J.E., «Nationalism, patriotism and diversity. Conceptualising the national dimension in Neil MacCormick's post-sovereign constellation», RECON Online Working Paper 2011/07, marzo de 2011, http://www.reconproject.eu/main.php/RECON_wp_1107.pdf?fileitem=5456460. 
plejo normativo formado por Tratados y Constituciones como Unión Constitucional ${ }^{17}$; POIARES MADURO tiene un desarrollo muy sugerente en el que se habla del Derecho contrapuntual ${ }^{18}$; VON BogDANDY escribe sobre constitucionalismo dual y complementariedad de constituciones ${ }^{19}$; Cruz Villalón explica el pluralismo como un diseño metaconstitucional e intertextual en el que unos textos normativos remiten a otros ${ }^{20}$; Rafael Bustos GisBERT ha expuesto su modelo de Constitución-red ${ }^{21}$; Lo interesante es entresacar los elementos comunes de todos ellos, que son muchos, y dibujan una concepción común en la que no hay una única fuente de legitimación constitucional, sino un sistema que funciona a veces coordinada, a veces enfrentadamente, pero, en teoría, al servicio de la realización de fines constitucionales. Para entender el pluralismo constitucional, personalmente me ha sido de mucha utilidad la concepción de Neil WALKER. Este autor habla de un pluralismo constitucional que identifica lugares metaconstitucionales en interacción, a través de una construcción teórica que quizás está menos estructurada que las anteriores, pero que sirve para explicar también la formación de sistemas federales anteriores a la forja de lo supranacional y que, por ello, puede adaptarse para analizar otros sistemas de poder constitucional distintos de los del Estado o del de la integración europea ${ }^{22}$. Los diferentes elementos del constitucionalismo tienen que discurrir por una serie de transiciones para adaptarse a ese modelo pluralista del que, no lo olvidemos, el Estado como tal sigue siendo parte.

Pero, todo hay que decirlo, el pluralismo constitucional tampoco es la panacea ni el fin de los males del déficit de legitimidad democrática en Europa. Un gran defecto que tiene es que su desarrollo teórico no está acompañado de una transformación real de la cultura democrática, ni de las instituciones estatales, ni de las supranacionales, ni de la supuesta ciudadanía europea. Esos ciudadanos europeos siguen ajenos a la exigencia de participación, que es lo que impulsaría la creación de un auténtico tejido democrático, y aquí vuelvo a coincidir con Pedro CRUZ cuando atribuye al déficit de espacio público, más que a la ausencia de demos, las taras de legitimidad democrática $^{23}$. Como esto sigue ocurriendo, no es suficiente la participación ciudadana

${ }^{17}$ Pernice, I., «Multilevel consitutionalism in the European Union», European Law Review, vol. 27, 2002, pp. 511-529. También, PERnICE, I, «Multilevel constitutionalism and the Treaty of Amsterdam: European Constitution-making revisited?», Common Market Law Review, núm. 36, 1999, pp. 703-750.

${ }_{18}$ Poiares Maduro, M., «Las formas del poder constitucional», Revista de Estudios Políticos, núm. 119, 2003, pp. 11-55.

${ }^{19}$ Von Bogdandy, A., «Constitutional principles»..., op. cit., pp. 34 y ss.

${ }^{20}$ Cruz Villalón, P., La Constitución inédita..., op. cit., p. 139.

${ }^{21}$ Bustos Gisbert, R., La Constitución Red: un estudio sobre supraestatalidad y constitución, Instituto Vasco de Administración Pública, Oñati, 2005.

${ }^{22}$ WALKer, N., «The idea of Constitutional Pluralism», The Modern Law Review, vol. 65, núm. 3, 2002, pp. 317-359, p. 337.

${ }^{23}$ Véase supra \&. nota 1. 
vía Estados miembros. Por más que el Tratado de Lisboa, siguiendo una tradición ya firme de asimilación del lenguaje constitucional, haya incorporado más elementos constitucionales al texto de los Tratados y, en consecuencia, a su presentación en sociedad, muchos de esos elementos están incompletos y son más nominales que reales. Una prueba, entre otras que se expondrán a continuación, cuando se analice el modelo institucional, es el artículo 51 de la Carta de Derechos Fundamentales de la Unión. Cuando dicho artículo explica que los derechos solo vinculan a la Unión y a los Estados «cuando aplican el derecho de la Unión», hay muchas incógnitas que se abren. Por ejemplo, qué ocurre con la aplicación de la ley de transposición de una Directiva europea. ¿Es derecho de la Unión? Formalmente al menos es derecho estatal. Materialmente, sin embargo, es difícil dudar de su carácter de derecho de la Unión. ¿No hace pensar una restricción así, como esta, que los ciudadanos europeos estamos divididos en dos y que nuestros derechos europeos son, de manera sospechosa, elementos objetivos de legitimación del poder supranacional, pero no derechos subjetivos en el pleno sentido del término. Por último, y volvemos al mismo sitio que en el subapartado anterior, la ratificación unánime y a través del sistema clásico de incorporación de Tratados ancla la integración constitucional en esquemas propios del sistema iusinternacional clásico. No solo es que la ciudadanía no esté inmediatamente presente en la ratificación, excepto en algunos Estados que exigen referendo para ello. Es que ni siquiera hay una autonomía cierta en ese aspecto del Derecho de la Unión que sería necesaria para cerrar el modelo en un sentido federal y para que los complejos normativos autónomos, estatales y supranacional, equilibrasen sus posiciones en la interacción que conlleva su convivencia. Pero la exigencia de unanimidad en las ratificaciones de las reformas de los Tratados cancela la autonomía del sistema supranacional. El Tratado constitucional, que nunca entró en vigor, introdujo un sistema de ratificación en el que la unanimidad se ponía en duda. Y lo hacía cuando se dejaba al Consejo Europeo «examinar la cuestión» en caso de que hubiera Estados que en dos años no hubiesen culminado la ratificación (artículo IV-443 TeCE). Ese mecanismo abrió una puerta a la concepción autónoma que se cerró antes de que nadie pasara. El portazo fue no solo de los referendos francés y holandés a ese Tratado -porque el sistema de reforma no unánime se recuperó en el actual 48 TUE-, sino, sobre todo, del segundo referendum irlandés de ratificación del Tratado de Lisboa. Es decir: ya sabemos que lo que significaba la referida cláusula era que bien se abandonaría la reforma proyectada en caso de que un Estado no estuviera de acuerdo, bien se convencería al país boicoteante para que se lo pensara mejor. Las reformas simplificadas del IV-444 TcCe, que también ha dejado a salvo Lisboa, avanzan algo en este aspecto de la autonomía, pero no tanto como para poder considerar que se haya pasado a un modelo que prescinda del sistema clásico de ratificación, en el que son los Estados los que habitan y deciden. Y, para más inri, el Tribunal Constitucional Federal alemán dejó claro en su sentencia Lisboa que el Parlamento alemán 
no solo no descuidaría sus facultades para escrutar cualquier reforma de los Tratados, sino que las revisiones simplificadas tendrían que ser especialmente escrutadas por las cámaras $\mathrm{y}$, al efecto, estableció las condiciones de dicha intervención en defensa del principio democrático ${ }^{24}$. En definitiva: al pluralismo constitucional, que puede explicarse normativamente a través de las Constituciones y los Tratados, le falta estar acompañado de una transformación real del tejido democrático y, como veremos, también del institucional.

\section{LA LEGITIMACIÓN INSTITUCIONAL}

Además de la legitimación a través del Derecho, la legitimación democrática del poder en los Estados constitucionales tiene otro en la designación por parte de los ciudadanos de aquellos que van a ejercerlo en su nombre. Esta vía de legitimación se complementa a través de los mecanismos de control y de exigencia de responsabilidad de los representantes elegidos. Estos, una vez designados, se integran en las instituciones titulares de los poderes legislativo y ejecutivo, pudiendo ser la elección bien directa, bien indirecta como ocurre con la designación del gobierno en los sistemas parlamentarios. Continuando con el referente de la Unión Europea como ejemplo de comunidad política donde se ejercen poderes legislativos, ejecutivos, y judiciales, a escala supranacional de manera institucionalizada se puede trazar un esquema de legitimación. Como es sabido, las instituciones supranacionales europeas responderían a modelos de legitimación institucional variados: indirecto en el caso del Consejo, integrado por representantes gubernamentales de los Estados miembros; doblemente indirecto para la Comisión, en cuya designación intervienen los ejecutivos estatales a través del Consejo Europeo y el Consejo, así como el Parlamento Europeo, el cual también tiene funciones de control; finalmente el Parlamento Europeo es la única institución designada a través de sufragio universal directo, por lo que si la Unión siguiera la lógica del parlamentarismo democrático debería ser la institución central. Pero esto último, huelga decirlo, no es así.

El sistema de gobierno europeo no reproduce los esquemas de las democracias representativas, presidenciales o parlamentarias. Este hecho tiene una explicación histórica y otra funcional, pues en la creación de las Comunidades en los años cincuenta se optó por una integración económica en lugar de hacerlo por una directamente política y, en función de eso, las instituciones fueron diseñadas para dar impulso a los objetivos de eliminación de barreras económicas y creación de un mercado común. Sin embargo, ese diseño institucional originario, que ha evolucionado a medida que lo ha hecho el proceso

${ }^{24}$ Véase López CAStillo, A., «Alemania en la Unión Europea a la luz de la sentencia Lisboa del TCFA» en López CAstillo, A. y Menéndez, A. J., Sentencia Lisboa del Tribunal Constitucional Federal Alemán, Centro de Estudios Políticos y Constitucionales, Madrid, 2011, pp. 19-58, pp. 43 y ss. Sentencia Lisboa, BVerfG, 2 BvE 2/08 de 30 de junio de 2009 . 
de integración, en cierto sentido es el lastre que arrastra la legitimación de la Unión, pues siempre da la razón a los que hablan de su déficit democrático. El sistema institucional europeo sigue cambiando y buscando encajes distintos que lo acerquen más al parámetro de legitimidad propio de las democracias parlamentarias. Pero lo consigue solo a medias. Sobre el modelo institucional originario europeo, que presentaré a continuación en primer lugar, se ha superpuesto recientemente un nuevo modelo integrado. Este último pone a los parlamentos nacionales a funcionar dentro de los mecanismos de toma de decisión europeos e intenta, entre otras cosas, ofrecer una nueva entrada de legitimidad o lo que utilizando la terminología anglosajona propia de la Ciencia Política se considera un input de legitimidad.

\subsection{El modelo institucional europeo: Consejo, Parlamento y Comisión}

El Tratado de la Unión, tras su reforma lisboeta, y precisamente en el título consagrado a los principios democráticos, propone un modelo federalista en su artículo 10. Dicho sistema tiene en el Parlamento Europeo la representación ciudadana y en el Consejo la representación estatal, como si se estuviera respondiendo a las aspiraciones que el Parlamento Europeo ya puso de relieve en los años ochenta cuando se elaboró el primer proyecto de Tratado de la Unión ${ }^{25}$. En teoría, esa federalización institucional es algo plausible. Por una parte, la representación gubernamental en el Consejo, a diferencia de lo que ocurre en otras organizaciones internacionales, es de gobiernos legitimados democráticamente a través de las cámaras parlamentarias de los Estados miembros ${ }^{26}$. Por otra, la generalización del procedimiento de codecisión, que ahora se llama ordinario, como procedimiento legislativo ha dado al Parlamento una posición casi pareja a la del Consejo en ese ámbito. Además, el Parlamento tiene facultades de control sobre la Comisión, en especial a través de la moción de censura destructiva -artículos 17.8 TUE y 234 TFUE-. Puesto que la designación del presidente de la Comisión en realidad está condicionada por la propuesta del Consejo Europeo y, en consecuencia, por los acuerdos entre los Estados miembros, la moción de censura le da al Parlamento un arma para la exigencia de responsabilidad sobre ese gobierno técnico de la Unión que es la Comisión.

En esa presentación federal del diseño institucional de la Unión que ha salido de Lisboa se hallan también referencias a otros principios y mecanismos

${ }^{25}$ El Proyecto Spinelli (1984), que «proponía una amplia reforma institucional con un esquema en el que el Parlamento Europeo tuviese poder legislativo y un poder real de control político, una Comisión con funciones más o menos semejantes a las de un gobierno y un Consejo transformado en una institución similar a una segunda cámara». ALDEOCA LUZÁRRAGA, F., La integración europea. Análisis histórico-institucional con textos y documentos, vol II. Génesis y desarrollo de la Unión Europea (1979-2002), Tecnos, Madrid, 2002, p. 80.

${ }^{26}$ Von Bogdandy, A., «The European Lesson...», op. cit., p. 16. 
de profundización democrática, singularmente la transparencia o la iniciativa legislativa popular. Sin embargo, tal presentación es en realidad bastante tramposa $^{27}$. Cuando se sigue leyendo el Tratado, se comprueba que el equilibrio institucional que se había modificado al encumbrar al Parlamento Europeo en detrimento del Consejo y, en consecuencia, dando a la Comisión un margen de maniobra mayor como gobierno técnico, ha vuelto a ser compensado. Escora de nuevo hacia un diseño en el que se privilegia la capacidad de decisión de los ejecutivos estatales. ¿Cómo? Pues con la inclusión del Consejo Europeo en el cuadro institucional, según se especifica en los artículos 13 y 15 del Tratado de la Unión.

El Consejo Europeo interviene por derecho propio tanto en la designación del presidente de la Comisión, como en la del Alto Representante para Asuntos Exteriores, que es miembro nato de la misma. Estas potestades le dan al Consejo Europeo un control sobre la Comisión que parecía haber ganado el Parlamento, pero que en realidad sigue estando en manos de los ejecutivos estatales. A esta realidad se une otra conocida, que es que la calidad representativa del Parlamento Europeo se muestra insuficiente, con unas elecciones de bajos índices de participación y circunscripciones estatales que fomentan que las campañas electorales se centren más en rencillas internas de partidos de dimensión nacional antes que en la política o las políticas europeas, las cuales siguen siendo cuestión de los Estados representados en ambos Consejos. La representación en el Parlamento Europeo es fruto de controversias y quinquenales decepciones. Por mucho que pueda aceptarse que el europeo no tiene por qué ser o reproducir fielmente la configuración de un parlamento nacional, no se debería renunciar a mejorar su estatus, su grado de representatividad y, en definitiva, su conexión con los ciudadanos europeos. Hay que exigirle que siga reivindicando protagonismo institucional puesto que el Parlamento Europeo tiene mucho que aportar a la legitimación democrática del poder supranacional. Para eso habría que potenciar algo que ya se ha reseñado: el espacio público europeo y, a su través, el sujeto público supranacional. Ahora valoraré si a eso contribuye, o más bien no, el modelo integrado que se presenta a continuación.

\subsection{El modelo institucional integrado: la incorporación de los parlamen- tos nacionales}

En un orden supranacional en el que los Estados miembros tienen en común un sistema parlamentario de gobierno, la incorporación de los parlamentos nacionales al funcionamiento del mismo tiene dos significados: por una parte es un retoque sutil del modelo institucional anterior cuyo sentido hay que descifrar; por otro, responde de manera directa a demandas que esos

${ }^{27}$ Véase el análisis de esta presentación federal de la Unión en Von Bogdandy, A., «The European Lesson...», op. cit. 
parlamentos nacionales llevan haciendo desde los años noventa. Los parlamentos nacionales han sido desde el punto de vista político los grandes perjudicados por la integración, perdiendo capacidad de reacción ante la adopción de regulaciones que se negocian en los Consejos y se convierten en derecho interno con su sola aprobación. En parte esa privación puede atribuirse al diseño institucional y mecanismos de toma de decisión en la Unión, pero en parte también a la laxitud con la que algunas cámaras han venido ejerciendo el control parlamentario de la participación de sus gobiernos en el Consejo. La voz de los parlamentos nacionales en Europa estuvo canalizada durante un tiempo a través de organizaciones interparlamentarias de carácter paracomunitario, singularmente la Conferencia de Comités para asuntos de la Unión de los Parlamentos de la Unión Europea-COSAC-. Pero en Lisboa a las asambleas legislativas estatales se las ha incluido en el plan de europeización que desde un principio se proyectó sobre los gobiernos, con su participación en el Consejo, y a los jueces, responsables comunes de la aplicación del derecho europeo y excepcionales actores para el control de la legalidad del mismo a través de la cuestión prejudicial. Pero a la incorporación de los parlamentos nacionales parece pedírsele algo más que un sentido europeizador, puesto que la idea de profundización democrática está anudada a dicha incorporación, como se señala en el artículo 12 del Tratado de la Unión.

Así es: el artículo 12 del actual Tratado de la Unión otorga a los parlamentos una serie de atribuciones entre las que están la participación en la reforma de los Tratados, la participación en los mecanismos de control del principio de subsidiariedad, la participación en los mecanismos de evaluación de las políticas del Espacio de Libertad, Seguridad y Justicia y, por último, la cooperación interparlamentaria entre ellos y con el Parlamento Europeo. Esta integración de los parlamentos en la vida democrática de la Unión refuerza la posibilidad de control y de influencia sobre los gobiernos nacionales, sobre las decisiones del Consejo, pero sobre todo da a los parlamentos nacionales una voz en el foro público europeo. Cuando a esto se une la inclusión de tímidos elementos de participación ciudadana, cual es la iniciativa legislativa popular que se proyecta en los artículos 11 del TUE y 24 TFUE, se busca algo que el Parlamento Europeo no logra lograr: la introducción de los asuntos europeos en la política cotidiana, la conexión con la ciudadanía, el refuerzo del espacio público y del sujeto público europeo.

No obstante, siendo consciente de que puede ser impopular no valorar como logro positivo que se hayan diseñado e implementado estos cauces de integración de los parlamentos nacionales en las dinámicas de la Unión Europea, en mi consideración la utilidad de ese cauce como input de legitimación es limitada. En contraste, y para atenuar lo impopular de mi valoración, diría que es plausible que mediante la participación de las cámaras parlamentarias estatales en los mencionados procedimientos se mejore la información que estas reciben sobre los asuntos europeos. Pero hay que considerar también que ese mayor protagonismo de los parlamentos nacionales hace sombra o 
compite con el del Parlamento Europeo y puede ir en su detrimento. En más de un sentido se produce una duplicación de funciones de control parlamentario. Sería más productivo que los parlamentos nacionales se quedasen con su función interna de control de sus gobiernos y el Europeo siguiese con la suya de control de las actuaciones del ejecutivo técnico, que es la Comisión, y, ¿por qué no?, ya que el equilibrio institucional europeo se ha balanceado de nuevo con la institucionalización formal del Consejo Europeo, quizás el Parlamento Europeo pueda aprovechar la obligación que tiene el Presidente del Consejo Europeo de informar al Parlamento tras cada reunión -art. 15.6 d) TUE-, para llevar a cabo un cierto control político de sus actuaciones, siquiera de cara a la opinión pública. La participación de los parlamentos nacionales puede ser no solo una pérdida de energía, teniendo en cuenta el ingente volumen de información que les llega de la Comisión, sino también una dilución de responsabilidad. A no ser que se consiga depurar los procedimientos de participación y que estos se reserven para cuestiones relevantes. Si por esa vía se reactiva el interés ciudadano en la política europea, bueno será, pero mis dudas respecto a la viabilidad del intento, expresadas quedan.

\section{LA LEGITIMACIÓN PROCEDIMENTAL}

Por último, en esta sección voy a dar cuenta de dos modelos de incidencia en la adopción de decisiones que están siendo experimentados casi de manera original en la Unión Europea y, como consecuencia, hacen de esta un referente para otras organizaciones que aspiran a ejercer o que ya ejercen poder supranacional. Me refiero por una parte a la gobernanza y por otra a la subsidiariedad. Bien es cierto que ninguno de los dos modelos puede ser considerado como procedimiento de legitimación democrática en sí mismo, no es que la Unión Europea esté sustituyendo los procedimientos legislativos por procedimientos basados en la gobernanza multinivel o en la subsidiariedad. Pero sí es cierto que, aun así, de ambos modelos se esperan inputs de legitimidad. Se espera que mejoren lo que he denominado algo más arriba la calidad democrática de las decisiones de la Unión. Y se entiende que esta mejora se realizaría a través de los principios de participación y de transparencia que inspiran ambos modelos. Desde mi punto de vista, ante ambos hay que guardar alguna cautela. ¿Por qué? Pues porque ninguno de los dos está basado en el principio de igualdad. Los fundamentos de ambos están en la exigencia de eficacia de las decisiones europeas, entendiendo que la eficacia es otro input de legitimidad, por más que no sea un input democrático. Por otra parte, otro de los fundamentos de ambos procedimientos, la necesaria toma en consideración de la opinión de los sectores o esferas de decisión directamente afectados por cada regulación, no debería llamar a engaño, pues el hecho de que algunos estén directamente implicados o sean destinatarios específicos de ciertas normas, no quiere decir que las consecuencias de la adopción de las mismas dejen de tener incidencia sobre el resto de los ciudadanos europeos, principales avalistas del carácter democrático de cualquier legitimidad. 


\subsection{El modelo de la subsidiariedad}

El principio de subsidiariedad, introducido en los Tratados a raíz de la reforma de Maastrich, anticipado por el Acta Única Europea y por la serie de informes y ensayos previos a esta, es de los elementos más controvertidos del complejo normativo europeo. En los años noventa el debate doctrinal en torno al principio, su significado y su viabilidad fue bastante intenso y, desde entonces, los ensayos para su implementación como principio de orden competencial en las relaciones entre la Unión y los Estados han sido variados. Desde un punto de vista teórico y siguiendo ciertas concepciones, el principio de subsidiariedad puede facilitar la organización democrática de un ente jurídico-político compuesto, federal o asimilado. Puede facilitarla en la medida en que promueve que los poderes públicos más cercanos al ciudadano se encarguen de las decisiones relativas a la vida ordinaria de estos y en la medida en que hace contrapesar las decisiones del poder público central con las exigencias de los poderes territoria$\operatorname{les}^{28}$. El principio de proximidad hace factible que se tenga en cuenta el contexto socio-cultural en el que se desarrolla esa vida, con lo que da al ciudadano un anclaje y estimula su participación, mientras que también impulsa la adscripción de esos ciudadanos y comunidades a la ciudadanía y a la comunidad de mayor extensión: esa comunidad ampliada y compuesta en la que los problemas globales son gestionados por poderes públicos supranacionales. De esta concepción, que es solo una de las muchas que hay en torno a la subsidiariedad, queda claro que es un principio que facilita la calidad democrática de las decisiones de los poderes públicos. Pero, y esto es importante, lo hace cuando hay órdenes de competencias organizados y diferenciados para los distintos poderes que sirven a ese ciudadano. La subsidiariedad confiere una legitimidad al ejercicio del poder político no porque esté conectada con el origen de ese poder, sino porque determina las competencias que ese poder puede ejercer legítimamente o, más bien, hasta qué punto puede ejercer esas competencias cuando las comparten dos entes distintos. La subsidiariedad como principio de legitimidad conlleva un riesgo anunciado: que se oculte el principio de igualdad porque el de eficacia de las decisiones del poder local o global sea el que impere.

${ }^{28}$ Constantinesco, V., se refiere a la subsidiariedad como principio o criterio de organización basado en la pluralidad de centros de actuación unidos, o relacionados, por una división de atribuciones. La subsidiariedad se ocupa, en un diseño así, de conferir o reconocer a cada ámbito de actuación aquellas atribuciones de las que es más capaz de hacer uso. Constantinesco, V., "Who's afraid of subsidiarity?», Yearbook of European Law, 1991, pp. 33-55, p. 34. Por su parte, para MACCORMICK hay una concepción de la subsidiariedad racional-normativa, consignada en el Tratado de Maastricht, que asegura la existencia de foros de participación democrática en ámbitos locales, regionales y estatales, evitando que las estructuras europeas ahoguen la existencia de las demás. MACCORMICK, N., Questioning Sovereignty..., op.cit., pp. 154-155. 
Lo mismo puede ocurrir si el principio de proximidad se impone como criterio de justificación. No obstante, estos riesgos deben estar compensados porque el principio de subsidiariedad opera dentro de un sistema jurídico e institucional que conllevan, como se ha descrito, sus propios inputs de legitimación.

Pero además de esa objeción general, que se deriva de la misma conceptuación abstracta del principio de subsidiariedad como elemento de profundización democrática, podemos señalar otras más que se derivan de la manera en la que la subsidiariedad aparece formulada y contextualizada en los Tratados europeos. Esa formulación añade un repertorio nada desdeñable de objeciones parciales a su potencial legitimador. En primer lugar, el principio de subsidiariedad en los Tratados y en el funcionamiento del orden europeo ha estado más orientado a ser un criterio de medición de eficacia de las decisiones que a ser un criterio de respeto del ámbito de realización democrático definido por el reparto competencial. Y, a pesar de las reformas introducidas por el Tratado de Lisboa y del mecanismo de control de la subsidiariedad en el que participan los parlamentos nacionales, sigue siendo así. Solo hay que ver el artículo 5 del Protocolo sobre la aplicación de los principios de subsidiariedad y proporcionalidad, cuando habla de las fichas de subsidiariedad que deben acompañar a los proyectos de actos legislativos europeos: esta debe incluir elementos de evaluación del impacto financiero, las cargas que puedan suponer tanto desde el mismo punto de vista financiero como desde el administrativo, indicadores cuantitativos y cualitativos que justifiquen la pertinencia de la medida para alcanzar los objetivos del Tratado y, por último sí, en caso de que se trate de una Directiva, los efectos que la misma puede tener sobre la legislación estatal o regional. En segundo lugar, el procedimiento de control de la subsidiariedad, que como se ha señalado ahora ha incorporado a los parlamentos nacionales y regionales, es en sí largo y complejo. Largo porque la intervención de los parlamentos nacionales obliga a dar plazos suficientes para que estos puedan pronunciarse. Complejo porque más de cincuenta cámaras legislativas han de pronunciarse sobre el ajuste competencial de proyectos normativos, que cuando no tocan varios ámbitos de competencia distintos es difícil saber si rozan o no ámbitos de competencia o estatales o hasta qué punto o si sobrepasan el límite de la atribución. Por otra parte, la mayoría de esos proyectos siempre son fácilmente justificables desde el punto de vista de la «mayor eficacia» de la acción global. Sobra explicar lo dificultoso que puede ser sacar conclusiones generales de más de cincuenta pronunciamientos que, además, estarán condicionados por la comprensión de la competencia propia que tenga cada cámara o cada país, cuando no por una distribución interna de competencias que tenga en cuenta las atribuciones de entes regionales. Y también hay que considerar lo difícil que es atinar con qué se entiende por subsidiariedad y que cada parlamento puede llevar su propia razón o interés a los informes que haga. Así, en lugar de defender la competencia estatal para impedir los abusos del poder 
europeo sobre las competencias compartidas, el procedimiento de control de la subsidiariedad puede acabar en cualquier otra batalla ${ }^{29}$.

Con todo lo dicho, parece que el principio de subsidiariedad es por ahora un bienintencionado esfuerzo para que la eficacia, como criterio de adopción de decisiones, no arrase el ámbito de acción estatal o regional y lo deje vacío. Pero no está contribuyendo decisivamente a la profundización democrática. Para quien quiera comprobarlo, remito a las conclusiones de carácter más bien técnico que se pueden leer cada año en los informes que la Comisión está obligada a hacer, según el Protocolo, sobre la aplicación del principio.

\subsection{El inquietante modelo de la gobernanza}

Por último, hablaré sobre la virtualidad legitimadora de la gobernanza. Este mecanismo de toma o preparación de decisiones incide también en los ámbitos de competencia o actuación del poder público y busca la creación de redes de apoyo para las políticas supranacionales permitiendo que los actores afectados participen en el proceso de diseño de esas políticas y, en su caso, en la prefiguración de sus regulaciones ${ }^{30}$. La gobernanza no se orienta hacia la creación normativa sino hacia el ejercicio del poder, por lo que resulta una técnica óptima de gobierno o de preparación de decisiones a nivel supranacional, donde la normatividad requiere la intervención de los Estados, pero donde también se necesitan consensos previos que aseguren la adhesión a las directrices marcadas en la negociación ${ }^{31}$. En el caso de la Unión Europea, y en su conceptuación teórica, la gobernanza confiere legitimación a través de protocolos flexibles de adopción de decisiones que tienen en cuenta los intereses de los distintos sectores implicados en una cuestión concreta y los hacen intervenir. La gobernanza, ampliamente promovida como procedimiento óptimo de gestión política europea por parte de la Comisión y del Comité de las Regiones $^{32}$, facilita la pertinencia de las medidas adoptadas y acerca las deci-

${ }^{29}$ Opiniones anticipadas en Peters, J., «National parliaments and subsidiarity: think twice», European Constitutional Law Review, núm. 1, 2005, pp. 68-72, p. 71; y HinososA MARTínez, L. M., «La regulación del principio de subsidiariedad en el Tratado Constitucional: espejismos y realidades», Revista de Derecho Comunitario Europeo, núm. 19, 2004, pp. 787-827, pp. 815-816.

${ }^{30}$ HÉritier, A., «Elements of democratic legitimation in Europe: an alternative perspective», Journal of European Public Policy, 6:2 (1999), http://dx.doi.org/10.1080 /135017699343711, pp. 269-282, p. 273.

${ }^{31}$ Czempiel. E., «Governance and democratization» en Rosenau, J., y Czempiel, E., (eds.), Governance without Government: Order and Change in World Politics, Cambridge University Press, Cambridge, 2000, pp. 250-271.

${ }^{32}$ El impulso inicial lo dió la Comisión en 2001 con la publicación de la Comunicación de la Comisión, de 25 de julio de 2001, «La gobernanza europea-Un Libro Blanco» [COM (2001) 428 final-Diario Oficial C 287 de 12.10.2001]. El Libro Blanco del Comité de las Regiones sobre la gobernanza multinivel, aprobado en el pleno del 18 y 19 de junio de 2009, puede consultarse en la siguiente dirección web: http://www.europarl.europa.eu 
siones de los poderes públicos supranacionales a los grupos sobre los cuales dichas decisiones van a repercutir de manera más inmediata. La legitimidad que aporta la gobernanza no se fundamenta en un principio democrático, sino en un principio de eficiencia. Eso, creo, está bastante claro. La gobernanza remite a la eficiencia funcional de las decisiones tomadas a través de la interconexión de las distintas redes y sectores implicados en las políticas concretas, bien públicos, bien privados. Con ella, al sistema representativo parlamentario se le superpone otro sistema de representación no basado en el principio de igualdad y basado en la afectación de intereses sectoriales o territoriales. Dicha superposición en principio facilita la gobernabilidad, pero no puede decirse que con ella tenga por qué haber un incremento sensible de la calidad democrática de las decisiones ${ }^{33}$. En el caso de la Unión, la regulación de ciertos ámbitos de competencia europea se lleva a cabo a través de procesos de negociación, coordinación e incluso autorregulación, de los que la Directiva sobre derechos de autor que tomé como ejemplo anteriormente es una muestra. Esto significa que ámbitos de competencia europeos, sobre todo económica, pero no solo, son reglados a través de procedimientos en los que al control democrático se suma el control de la eficacia a través de las evaluaciones de impacto. La Comisión tiene un amplio margen de discrecionalidad a la hora de decidir a quién consultar ${ }^{34}$. Por otra parte, en la medida en que la implementación de dichas regulaciones se lleva a cabo casi mayoritariamente en los Estados y por los propios Estados aunque su origen sea europeo, esa ejecución se queda sin control parlamentario, observada en todo caso por la Comisión.

Este modelo de la gobernanza, más allá de la apertura al dialogo o la ampliación de la deliberación no aporta otros ingredientes de profundización democrática. Al contrario, tiene componentes de participación sectorial, incluso corporativos, y fomenta el uso de regulaciones de soft law, líneas de actuación y directrices, en defecto o en anticipación de una legislación propiamente dicha. Estas son las razones por las cuales yo anotaba que el modelo es inquietante. Considero que la gobernanza, como técnica de gobierno, tiene que ir acompañada de un refuerzo del control democrático. Y vuelvo a apelar al Parlamento Europeo. Cuando los artículos 11 del Tratado de la Unión y 24 del Tratado de Funcionamiento, siguiendo una línea abierta por la Comisión

/meetdocs/2009_2014/documents/afco/dv/livre-blanc_/livre-blanc_es.pdf. Sobre la gobernanza multinivel y su funcionamiento concreto a nivel regional, véase el trabajo de TUÑón, J., (ed), Iglesias, M., RoldÁn, J., Dandoy, R., y CARMOna, A., Gobernanza multinivel: el reto de las regiones mediterráneas. Una perspectiva andaluza, Consejería de la Presidencia de la Junta de Andalucía, Sevilla, 2011.

${ }^{33}$ Morata, F., «Governanza multinivel en la Unión Europea», VII Congreso Internacional del Centro Latinoamericano de Administración para el Desarrollo sobre la Reforma del Estado y de la Administración Pública, Lisboa, Portugal, 2002, http://unpan1.un.org/intradoc/groups/public/documents/CLAD/clad0044413.pdf, p. 11.

${ }^{34}$ MoratA, F., «Governanza multinivel en... », op. cit., p. 4. 
en los noventa ${ }^{35}$, hablan de la profundización en la vida democrática a través de la transparencia, al mismo tiempo sugieren que tanto las amplias consultas de la Comisión a los afectados por sus iniciativas, como el diálogo con organizaciones de la sociedad civil van a ser los factores de refuerzo democrático. No digo que no lo sean en ninguna medida, digo que me inquietan si suponen una renuncia a que el diseño jurídico e institucional de la Unión siga avanzando hacia un modelo en el que la legitimación democrática sea cada vez menos lewiscarrolliana. Me inquietan afirmaciones sobre la gobernanza en la Unión que conciben que, al no ser la Unión un Estado, las formas de legitimación que han de sustentar su actividad tienen que ser distintas. Me inquieta que las sociedades occidentales, a las que tanto les ha costado conquistar los Estados y convertirlos en democracias, nos acabemos orientando más hacia un principio de buen resultado que hacia uno de igualdad. Y sobre todo me inquieta que lo justifiquemos dicendo que se les preguntó a los directamente afectados. Por eso el modelo de la gobernanza, que por supuesto sí tiene aportaciones importantes en la mejora de la gestión porque racionaliza la preparación de regulaciones sectoriales, no puede ni debe funcionar sino acompañado de un diseño y de un funcionamiento institucional en el que el Parlamento Europeo diga y tenga que decir, de modo que también se asegure la firmeza de la normatividad reguladora de cuestiones tangente con los elementos centrales de lo constitucional ${ }^{36}$.

\section{CONCLUSIÓN}

Supongo que el haber utilizado este método de presentar varios modelos de legitimación, sus aportaciones y sus contrapartidas, me da ventaja para poder terminar este discurso sin contradecir la premisa de partida: la inexistencia de la legitimación democrática del poder supranacional. También me da la ventaja de no tener que asumir mayor responsabilidad, pues al final lo que hago no es sino arrojar encima de esos modelos que he ido repasando -todos imperfectos, incompletos y parciales- la culpa de que no se pueda dar una explicación unívoca sobre el asunto de la legitimidad democrática en la Unión.

${ }^{35}$ Se trata del programa de transparencia, que intenta crear apoyos para las políticas europeas a través de la información sobre las mismas que se va diseminando. HÉRITIER, A., «Elements of democratic legitimation... », op. cit., p. 271.

${ }^{36}$ Como afirma HÉRITIER, al haber medidas que requieren estar insertas en procesos de toma de decisión democráticos -como pueden ser las medidas de política fiscal y monetaria- «la situación requiere medidas institucionales que suministren un terreno para contrarrestrar la tendencia a la segmentación y la búsqueda del interés particular. Tales medidas serían, después de todo, reforzar el Parlamento Europeo para tener en mente los aspectos generales de las políticas interrelacionadas». HÉRITIER, A., «Elements of democratic legitimation... », op. cit., p. 280. 
No obstante, creo que no es del todo así, es decir, el análisis mira para otros lados, pero para enfocar las vías de legitimación que se muestran más proclives a facilitar la profundización democrática, el fomento del espacio público europeo y el protagonismo de sus sujetos. El poder supranacional tiene dos vías abiertas para su conversión democrática: el pluralismo constitucional como marco jurídico de legitimación y el Parlamento Europeo como elemento de conexión con la ciudadanía. Sin esos dos impulsos, la transparencia y el estímulo de participación que promueven los procedimientos de la subsidiariedad y la gobernanza no calarán. El pluralismo constitucional, aun con las fallas que se le han señalado, traza un camino de futuro y es capaz de abarcar elementos positivos de otros modelos. Es óptimo para incluir el modelo institucional europeo, el procedimental de la subsidiariedad o las aportaciones de la gobernanza, y para encajarlos en un esquema vertebrado por la participación ciudadana como fundamento y por el sistema de derechos, a la vez fundamento y medida de control. Por otra parte, también se ha insistido en la centralidad del Parlamento Europeo y en que es la apuesta más lógica para lograr una legitimación democrática. Eso sí: la apuesta exige convertir al Parlamento Europeo en un verdadero órgano de representación, si no de las mayorías y minorías políticas tal y como se conciben los parlamentos nacionales, que ¿por qué no?, sí de una ciudadanía europea que vaya haciéndose reconocible. Nada de esto puede hacerse sin trabajar a la par con los elementos integrantes de esa ciudadanía o identidad europea, conseguir que madure lo suficiente como para que sea algo más que un apósito, y ese trabajo pasa por la consolidación del espacio público europeo. Este momento de crisis puede ser decisivo para esa labor y mis dudas quedan expresadas sobre si los parlamentos nacionales son el foro apropiado para contribuir a ello.

Por último, si la legitimidad democrática no, al menos está bastante claro que el poder supranacional sí existe. En todo momento he utilizado a la Unión Europea como referente porque es el sistema supranacional que ejerce poder político más desarrollado que se conoce hasta el momento, pero ni es el único ni van a dejar de surgir otros a medida que avance el siglo. No sé si somos del todo conscientes de que la globalización hace realmente necesario que haya poderes supranacionales, poderes que gestionen intereses globales, pero que eso no significa que tales poderes puedan librarse de estar sometidos a controles democráticos. La Unión, que es un referente para muchas organizaciones internacionales existentes, está en la vanguardia de la adopción de regulaciones globales, pero ya hemos visto a través del ejemplo de la Directiva de propiedad intelectual que la Unión no garantiza una calidad democrática del mismo grado que la de los Estados que la componen. Uno puede preguntarse: ¿es necesaria una regulación a nivel europeo de la propiedad intelectual y de su protección? Y puede contestarse: sí. Pero tampoco es descabellado afirmar que es necesario un acuerdo para proteger la propiedad intelectual cuyo vector normativo no sea únicamente la protección del beneficio comercial. ¿Es exigible que una regulación de tal tipo tenga legitimidad democrá- 
tica? La respuesta es sí: no olvidemos que hablamos de afectación de derechos a la libre comunicación. ¿Se quedaría callada Alicia cuando le digan que su problema no es problema, que el grado de legitimidad democrática es un criterio intercambiable por la eficacia o la transparencia y que cambie de lugar en la mesa de la fiesta? Yo diría que no, que no se lo pensaría y se iría a buscar razones a otro lugar.

Nueva York, 15 de junio de 2012 